\title{
DEVEMOS APROXIMAR QUESTÕES SOBRE ÉTICA E DIREITOS ANIMAIS À EDUCAÇÃO AMBIENTAL? O QUE PENSAM EDUCADORES AMBIENTAIS BRASILEIROS SOBRE ESSE TEMA ${ }^{1}$
}

\author{
Maria Castellano ${ }^{2}$ \\ Marcos Sorrentino ${ }^{3}$
}

Resumo: Nos últimos anos, tem se ampliado na academia a abordagem de questões relativas às formas como nos relacionamos com os outros animais. Autores dessas áreas reconhecem a pertinência de uma aproximação desse campo com o da educação ambiental, tanto pela convergência de princípios quanto pelas inter-relações pragmáticas entre elas. Entretanto, aproximá-las não tem sido trivial, em parte por dificuldades trazidas pelas próprias questões sobre nossas relações com os outros animais, e, em parte, por alguns entendimentos pouco ousados sobre a educação ambiental, seu papel e alcance. A partir dos resultados de uma série de questionários, o presente trabalho traz uma perspectiva sobre o que pensam educadores brasileiros sobretudo educadores ambientais - sobre essa aproximação, sendo que a maioria dos respondentes a considerou pertinente, ainda que, em vários casos, sob perspectivas um tanto conservadoras. $\mathrm{O}$ artigo propõe abordagens pedagógicas, visando superar as dicotomias e lacunas identificadas entre essas duas áreas, sugerindo a valorização do diálogo e a inspiração na perspectiva inclusiva e abolicionista dos estudos críticos animais como um caminho nesse sentido.

Palavras-chave: Educação ambiental. Educação humanitária. Estudos críticos animais.

\section{SHALL WE APPROXIMATE ISSUES CONCERNING ANIMAL ETHICS AND RIGHTS TO ENVIRONMENTAL EDUCATION? WHAT BRAZILIAN ENVIRONMENTAL EDUCATORS THINK ABOUT THIS QUESTION}

Abstract: In recent years the approach to issues concerning how we relate to other animals has been expanded within the academia. Authors in these areas recognize the relevance of the approximation of this field to that of environmental education, due both to the convergence of principles between them, and to their pragmatic interrelationships. However, bringing them together has not been trivial, partly because of difficulties brought about by the very issues concerning our relationships with other animals, and in part due to some little audacious understandings of environmental education, its role and scope. From the results of a series of surveys, this study brings a perspective on what Brazilian educators - specially environmental educators - think about this approximation. The majority of respondents considered it relevant, although in some cases through an outlook somewhat conservative. The article proposes pedagogical approaches aimed at overcoming the dichotomies and gaps identified between these two

\footnotetext{
${ }^{1} \mathrm{O}$ presente artigo foi produzido com apoio da Fundação e Amparo à Pesquisa do Estado de São Paulo FAPESP, que deverá ser citado no artigo caso o mesmo venha a ser aceito para publicação.

${ }^{2}$ Doutora em Ciência Ambiental pela Universidade de São Paulo (USP). Pesquisadora em nível de pós-doutorado junto ao Departamento de Ciências Florestais da Escola Superior de Agricultura Luiz de Queiroz (ESALQ), Universidade de São Paulo, Piracicaba/SP; membro do Laboratório de Educação e Política Ambiental (Oca), USP/ESALQ.mcastelbr@gmail.com

${ }^{3}$ Doutor em Educação pela Universidade de São Paulo (USP). Docente junto ao Departamento de Ciências Florestais da Escola Superior de Agricultura Luiz de Queiroz (ESALQ), Universidade de São Paulo, Piracicaba/SP; Coordenador do Laboratório de Educação e Política Ambiental (Oca), USP/ESALQ.sorrentino.ea@gmail.com
} 
areas, suggesting the enhancement of dialogue and the inspiration in the inclusive and abolitionist perspective of critical animal studies as a path in that direction.

Keywords: Environmental education. Human education. Critical animal studies.

\section{¿DEBEMOS ACERCAR CUESTIONES SOBRE ÉTICA Y DERECHOS DE LOS ANIMALES A LA EDUCACIÓN AMBIENTAL? QUÉ PIENSAN EDUCADORES AMBIENTALES BRASILEÑOS SOBRE ESTE TEMA}

Resumen: En los últimos años, la academia ha ampliado el abordaje de las cuestiones relativas a las formas en que nos relacionamos con los animales. Los autores de estas áreas reconocen la importancia de un planteamiento de ese campo con la educación ambiental, tanto por la convergencia de principios como por las interrelaciones pragmáticas entre ellos. Sin embargo, acercarlos no ha sido trivial, en parte, por las dificultades provocadas por las mismas preguntas acerca de nuestra relación con otros animales, y, en parte, por ciertos entendimientos poco osados acerca de la educación ambiental, su función y alcance. A partir de los resultados de una serie de cuestionarios, este estudio aporta una perspectiva sobre lo que piensan educadores brasileños - educadores ambientales especialmente - en este enfoque, siendo que la mayoría de los encuestados la consideró relevante, aunque, en muchos casos, bajo perspectivas algo conservadoras. El artículo propone enfoques pedagógicos, con el objetivo de superar las dicotomías y los vacíos identificadas entre estas dos áreas, lo que sugiere la mejora del diálogo y la inspiración en la perspectiva inclusiva y abolicionista de los estudios críticos animales como un camino en consecuencia.

Palabras-clave: Educación ambiental. Educación humanitaria. Estudios críticos animales.

\section{Introdução}

Nas últimas décadas, questões relacionadas ao tratamento que damos aos animais não humanos têm se tornado cada vez mais proeminentes. Para além do que pode ser considerado como atos de crueldade ou maus-tratos isolados, o uso institucionalizado e, muitas vezes, industrializado de animais para diversos fins - tais como alimentação, experimentação científica, entretenimento e vestuário, dentre outros - que ganhou enormes proporções a partir do século XX e causa intenso sofrimento a bilhões de animais por ano, tem despertado questionamentos éticos de proporções crescentes.

Como consequência desse processo, abordagens pedagógicas capazes de contemplar essas questões também têm se ampliado em larga escala, sobretudo em algumas regiões do mundo. Segundo DeMello (2010), as relações entre humanos e os outros animais compõem um dos campo de estudos e educação que mais tem crescido na atualidade, ao menos na América do Norte.

Dentre os diversos conceitos utilizados para designar uma educação que considere questões referentes às nossas relações com animais não humanos encontra-se a educação humanitária $(\mathrm{EH})^{4}$ - um termo bastante utilizado no Brasil (sobretudo por instituições do

\footnotetext{
${ }^{4}$ Em países de fala inglesa utilizam-se, também, outros termos, tais como Anthrozoology, Animal Studies, HumanAnimal Studies (HAS), Critical Animal Studies (CAS), e Animals and Society Studies (DeMello, 2010), sendo que há algumas diferenças entre cada uma dessas abordagens - conforme mostram Nocella II et al. (2014), ao diferenciarem os HAS dos CAS. A opção, no presente artigo, por buscar definições e aplicações do conceito de educação humanitária dá-se pelo fato desse termo ter sido o mais comumente encontrado no Brasil quando instituições se referem a uma educação que inclua a abordagem de questões referentes aos animais não humanos.
} 
terceiro setor) - que, porém, carece de um arcabouço conceitual na literatura acadêmicocientífica nacional $^{5}$.

Nas últimas décadas, a produção sobre o tema tem mostrado algum incremento no contexto internacional, sendo que grande parte do material produzido vem de organizações não governamentais dedicadas à causa. No presente texto, tomamos como base as definições encontradas em livros de Zoe Weil (2004) e David Selby (1995), autores que têm se dedicado a explorar esse campo da educação de forma mais sistemática ${ }^{6}$.

As questões abordadas pela $\mathrm{EH}$ trazem, como lemos ao longo do presente texto, temas que - ao menos na opinião de alguns autores - deveriam ser objeto de trabalho também da educação ambiental (EA).

Assim, o presente artigo traz, em primeiro lugar, definições do conceito de $\mathrm{EH}$ a partir dos autores acima mencionados, bem como uma breve apresentação sobre os estudos críticos animais (CAS) e algumas diferenças entre ambas as abordagens que são pertinentes para a discussão em questão. Em seguida, são apresentados os principais elementos de uma EA crítica, buscando-se as correlações com o campo da educação voltada à ética e direitos animais - tanto na visão dos autores citados acima, como de autores brasileiros que, embora não necessariamente utilizem ou definam o termo educação humanitária, descrevem um campo semelhante ${ }^{7}$.

Em seguida, apresenta um panorama sobre o que pensam educadores ambientais brasileiros sobre essa aproximação, a partir de uma amostragem realizada ao longo da pesquisa da qual resulta a presente publicação (conforme descrito na seção 3).

Por fim, analisa os limites e potencialidades dessas aproximações, sugerindo próximos passos para superar as dicotomias existentes, considerando a abordagem dos estudos críticos animais como um possível caminho a ser contemplado juntamente com a EH e a EA na construção de um mundo mais sustentável, justo, e menos violento para todos os seres, tal como proclamado por essas vertentes educacionais.

\section{Da Educação Humanitária aos Estudos Críticos Animais: definições e diferenciações}

A educação humanitária (EH) encontra sua origem no século XVII, quando tinha como ideia central que a compaixão humana pelos animais beneficiaria outros valores sociais, pois aqueles que fossem bons para os animais o seriam, também, para com outros humanos. A aplicação da EH na educação infantil resultaria, assim, em uma sociedade mais compassiva e menos violenta (HUMES, 2008).

Segundo Unti e DeRosa (2003), as abordagens que partiram dessa concepção centravam-se na prevenção de atos individuais de crueldade até o início do século XX, quando

\footnotetext{
${ }^{5}$ Essa lacuna teórica não é de surpreender uma vez que, segundo Selby (1995), mesmo em países que estão entre os pioneiros no desenvolvimento da educação humanitária, como Estados Unidos e Canadá, o termo está praticamente ausente na teoria, e timidamente presente na prática (sendo que, nesse caso, o autor se refere aos currículos escolares). No Brasil, não temos encontrado publicações, nesse contexto, que se dediquem, ao menos parcialmente, a definir ou esclarecer esse conceito. Em textos acadêmicos em que aparece, o termo é tomado como já conhecido, e, a partir dele, levantam-se outras questões, de ordem ética e/ou prática. Ver, por exemplo, Souza (2012), Souza e Shimizu (2013).

${ }^{6}$ Tendo inclusive criado, no caso da autora, um instituto totalmente voltado ao tema (Institute for Humane Education), que disponibiliza programas de pós-graduação nessa área, bem como cursos, oficinas, informações e materiais pedagógicos (IHE, 2014).

${ }^{7}$ Conforme respostas à série de questionários I, descritos na seção 3 deste artigo.

${ }^{8}$ Pode-se fazer uma analogia dessa visão com as ideias de Kant, para quem os direitos dos animais eram indiretamente direitos de seus proprietários - ideal que reflete uma visão de mundo antropocêntrica e que ainda persiste, até hoje, em muitos contextos (ENGEL; JENNI, 2010; SANTANA, 2006).
} 
a industrialização da exploração animal - fazendas de peles, produção de animais para alimentação, e seu crescente uso para fins de experimentação científica - começava a surgir, demandando uma ampliação do foco da EH para abordar a questão da crueldade institucionalizada contra animais.

No período entre guerras, os movimentos anticrueldade, incluindo a $\mathrm{EH}$, perderam força frente a questões que pareciam mais urgentes, e, nas poucas iniciativas nas quais sobreviveu, esta voltou-se, essencialmente, aos animais de companhia, ressaltando os benefícios da convivência entre humanos e esses animais, e novamente, suas consequências positivas para a construção do caráter (UNTI; DeROSA, 2003).

Nas últimas décadas do século XX, outras questões relacionadas aos animais foram sendo incluídas no campo, paulatinamente, tais como aquelas referentes a animais silvestres em cativeiro, domesticação, uso de animais para entretenimento e alimentação (HUMES, 2008).

Paralelamente a essa ampliação do tema, nos anos 80, quando questões ambientais começaram a ganhar destaque globalmente, alguns educadores humanitários passaram a reconhecer os pontos de convergência dessa área com a educação ambiental (SELBY, 1995) e, nos anos 90, o escopo da educação humanitária começou a ser ainda mais expandido, explicitando as relações entre a educação voltada a questões raciais, de gênero, para os direitos humanos, para a paz e para o meio ambiente e aquela voltada aos direitos dos animais não humanos (HUMES, 2008; KAHN; HUMES, 2009). O campo estabelecia, assim, conexões entre diversas formas de violência e opressão, aproximando-se, em alguma medida, de sua proposta original (no que se refere à formação de caráter), porém, dessa vez, de uma maneira mais ampla e profunda.

O livro Earthkind: A teacher's Handbook on Humane Education, de David Selby (1995), em sua proposta de expandir a educação humanitária para além da abordagem das relações entre os humanos e os animais não humanos, incluindo princípios de justiça e compaixão também para com outros humanos e para com o planeta, apresentava diversos argumentos em favor da pertinência da aproximação da EH com cada uma das vertentes mais progressistas da educação acima citadas (a educação voltada a questões raciais, de gênero, para os direitos humanos, para a paz e para o meio ambiente), contribuindo para essa reorientação do campo. Para além disso, argumentava que tanto os pontos de convergência quanto as tensões entre a $\mathrm{EH}$ e as demais educações progressistas deveriam ser explicitados, de modo a diminuir, para a EH, a distância entre os objetivos anunciados e as realidades curriculares, e para as outras educações, aprimorar a compreensão das bases sobre as quais elas clamavam o direito de fazer parte do currículo escolar - isto é, os ideais de respeito à vida, à diversidade, às necessidades de cada ser; a explicitação das inter-relações entre diferentes formas de violência; e o fomento à compaixão e generosidade, dentre outras.

Da mesma forma, o livro de Zoe Weil The power and promise of Humane Education, publicado em 2004, reafirma a importância das conexões entre as diferentes educações progressistas, além de apresentar (assim como o livro de Selby) uma série de recursos e atividades práticas para se abordar essas interfaces pedagogicamente ${ }^{9}$. Essa autora identifica quatro elementos que, para ela, compõem as bases de uma educação humanitária de qualidade, dos quais fazemos uma síntese:

- oferecer informações verdadeiras, de modo que os estudantes ${ }^{10}$ possam compreender as consequências de suas decisões como consumidores e como cidadãos;

\footnotetext{
${ }^{9}$ Essa autora, trabalhando no campo da EH desde a década de 80, já havia feito outras contribuições para a área em publicações anteriores - datadas de 1990, 1994 e 2003.

${ }^{10}$ Aqui, utilizamos, conforme a autora, o termo estudantes, pois Weil (2004) trata a EH no contexto da educação formal - notadamente, dirigida a crianças e adolescentes.
} 
- fomentar a curiosidade, a criatividade e o pensamento crítico, de modo que possam avaliar a informação e resolver problemas com sabedoria;

- incentivar a reverência, fomentando a compaixão por todos; o respeito, visando conter desejos e impulsos imediatos; e a responsabilidade, para que tenham coragem de enfrentar os desafios atuais do planeta;

- oferecer escolhas positivas que beneficiem a todos - a si mesmos, a outras pessoas, aos animais e ao planeta - de modo que os estudantes se sintam empoderados para contribuir na construção de um mundo mais justo e solidário, ao invés de sucumbir ao desespero e impotência.

Para essa autora, a combinação desses quatro elementos é o que confere à educação humanitária seu real potencial transformador, permitindo que pensemos, nos importemos e atuemos com generosidade e integridade.

Para além da EH, e seguindo o amadurecimento do campo da educação voltada à ética e direitos animais, recentemente veio surgindo outra vertente educacional, em alguns países de língua inglesa, que está sendo denominada estudos críticos animais (CAS - da sigla Critical Animal Studies, em inglês) e que tem demonstrado relativo êxito na abordagem de questões referentes à opressão humana, não humana e planetária de forma integrada.

Embora como proposta geral se assemelhe bastante à EH, difere dela em alguns pontos que, possivelmente, tenham contribuído para um alcance mais amplo dos objetivos aos quais se propõe.

Uma primeira diferença é que, enquanto a educação humanitária tem seu foco prioritariamente nas crianças e jovens, os CAS tem sido dirigidos sobretudo a adultos ${ }^{11}$, considerando, assim como o faz a EA crítica no Brasil, que a aprendizagem se dá ao longo de toda a vida, e não apenas na infância e adolescência. Compreende-se, ainda, que essa abordagem traz a possibilidade de se criar e influenciar políticas públicas a curto prazo, uma vez que são formuladas por adultos. Essa compreensão também acompanha o amadurecimento do campo da EA, que vem migrando da ação exclusiva de educar crianças, para o trabalho com questões que têm incidência em políticas públicas.

Docentes que se propõem a abordar os CAS têm utilizado, como uma de suas estratégias para manter a amplitude de foco que a área demanda, a formação de grupos de trabalho entre docentes de diferentes áreas, visando elaborar propostas pedagógicas transdisciplinares e complementares. Assim, temas relacionados à violência e opressão às quais são submetidos animais não humanos, são abordados integradamente com questões ambientais, econômicas, de violência social e de trabalho, entre outras, por docentes de áreas tão distintas quanto artes, ciências, idiomas, direito etc.

Outro diferencial dos CAS é a não neutralidade com a qual se propõe a atuar nesse campo. Ou seja, enquanto há áreas que tratam das relações entre humanos e outros animais apresentando questões conflituosas, porém sem necessariamente se posicionar, os CAS deixam clara a posição contra tudo o que representa e inflige violência e opressão. Assim, em um exemplo concreto, em uma abordagem sobre modelos de produção alimentar, ao tomar posição por um modelo que seja o menos violento e opressor, os CAS serão explicitamente a favor daquele que seja baseado na produção de vegetais, na distribuição equitativa dos alimentos, na inclusão dos pequenos agricultores, na produção orgânica, no comércio justo, e assim por diante.

Os partidários dos CAS também são explicitamente abolicionistas, isto é, lutam pela libertação de toda forma de exploração e escravidão, humana e não humana (NOCELLA II et

\footnotetext{
${ }^{11}$ Essa informação, bem como outras aqui apresentadas sobre os CAS, provêm de entrevista realizada por uma das autoras do presente artigo com docente de uma universidade canadense onde foi implantado um curso de pósgraduação em CAS.
} 
al., 2014). Nesse sentido, diferenciam-se também da EH, uma vez que esta, muitas vezes, dá margem a abordagens bem-estaristas no que se refere aos animais não humanos ${ }^{12}$.

\section{Educação Ambiental Crítica e suas aproximações com a educação voltada à ética e direitos animais}

No Brasil, a educação ambiental crítica (EAC) tem suas origens no ambientalismo latino-americano, que, por sua vez, nasceu em um contexto de ditadura, em conexão e solidariedade a movimentos populares, tendo sido influenciado pelos movimentos sociais de contracultura das décadas de 60 e 70 (CASTELLANO, 2002). Assim, essa vertente da EA já emergiu dentro de uma compreensão sobre a indissociabilidade das questões ambientais e sociais, abrangendo, em sua complexidade, a necessidade de inclusão das diversidades - de espécies, de gênero, étnicas, sociais ou culturais - bem como conectada a valores de paz, solidariedade, autonomia, empoderamento e cidadania.

Trata-se de uma educação ambiental com base popular, socialmente comprometida e engajada (ARAÚJO et al., 2005), que fomenta o questionamento e o esclarecimento emancipatório de sujeitos e grupos, por meio do desvelar de argumentos, princípios e significados (TASSARA; ARDANS, 2005). Propõe-se a valorizar a compreensão do caráter histórico das interações sociais e dos processos de poder e dominação neles envolvidos, tornando visíveis os tipos de relações sociais e políticas que lhes são constitutivas, bem como as razões e mecanismos através dos quais elas se reproduzem ou se modificam (TAVOLARO, 2005). Nessa perspectiva, é uma educação ambiental avessa aos processos de alienação, no sentido do termo explicitado por Lima (2008).

A EAC fomenta, portanto, a horizontalidade das relações (sociais e pedagógicas) - não apenas como fim, mas também como meio - como forma de minimizar as assimetrias de poder que pautam as relações ambientais e sociais predominantes.

Caracterizando-se por orientar-se pela constante crítica aos modelos e relações sociais, à organização política e econômica e às formas de apropriação da natureza e da vida como um todo, a EAC promove a autocrítica permanente, colocando em constante revisão seus próprios pressupostos e práticas.

Ao abrir-se para esses questionamentos, ganha uma força transformadora e libertária que é não apenas convergente, mas, também, necessária na educação humanitária, e nos movimentos sociais em prol dos direitos animais e da vida como um todo.

No que se refere a uma aproximação com esse campo, portanto, desde suas origens a EAC compreendia que uma visão preservacionista da questão ambiental ficaria limitada a tentar gerenciar o ônus da crise socioambiental, ao invés de compreendê-la em sua complexidade e atuar em suas causas (LEIS, 1999; REPEC/CEAAL, 1994). Por esse motivo, suas demandas são de reconstrução política, em oposição às formas de poder que tenham por base relações de dominação, posição que converge com as atuais demandas dos movimentos sociais e da educação voltados a uma ética que defenda todas as formas de vida. Desde suas origens, a EAC tem se posicionado contra a lógica de exploração e mercantilização da vida, explicitando a

\footnotetext{
$12 \mathrm{O}$ bem-estarismo é a perspectiva que tem como fim a adoção de medidas de regulamentação do uso de animais, tendo como foco minimizar seu sofrimento nas diversas situações em que os humanos os exploram. $\mathrm{O}$ abolicionismo, por sua vez, visa o fim de toda e qualquer exploração, uso e privação de liberdade dos animais ainda que isso seja feito em condições humanitárias. Essa diferenciação conceitual é uma simplificação, havendo diversas nuances entre uma visão e outra, e as implicações práticas de cada uma delas ainda geram polêmica dentro do próprio movimento animalista. Nesse sentido, ver Brügger (2009); Felipe (2010); Francione e Garner (2010); Greif (2009); e Naconecy (2009).
} 
necessidade de se educar para uma nova ética, que respeite a vida em todas as suas formas ${ }^{13}$ embora, na prática, essa questão não tenha sido incorporada, de forma satisfatória, na maioria dos programas, projetos e ações de EA no país.

Entre os educadores humanitários, tanto Selby (1995) como Weil (2004) apontam que há convergências pragmáticas entre questões relacionadas ao respeito à vida coletiva e individual de animais humanos e não humanos, e questões ambientais, cujas consequências negativas vêm se acentuando a cada dia. Assim, há uma série de questões abordadas pelos educadores humanitários que têm implicações ambientais, tais como os efeitos da criação intensiva de animais para alimentação, no contexto de mudanças climáticas, na poluição de recursos hídricos e no desmatamento; as ameaças dos desequilíbrios ecológicos, colocadas pela caça e tráfico de animais, pela sobrepesca, pela perda de habitats e uso de pesticidas; a proporção de trabalho escravo utilizada, ainda hoje, na atividade pecuária, entre outros fatores.

Nesse sentido, Selby (1995) aponta que a inclusão de uma perspectiva da educação humanitária junto à EA poderia contribuir para a construção de sociedades sustentáveis, a partir de uma revisão crítica dos padrões de produção e consumo e suas inter-relações com uma ética de valorização da vida - em particular, indica a necessidade de se propor uma transição para modelos de produção alimentar baseados em vegetais, tema que tem ganhado atenção em vista dos efeitos devastadores da produção industrial de alimentos de origem animal.

Para além dessas convergências, Weil (2004) traz, também, propostas metodológicas que se assemelham a algumas que têm sido utilizadas pela EA crítica. Sugere, por exemplo, que mudar os formatos dos encontros (desde a disposição dos móveis na sala de aula, ou a iluminação, até propor atividades extraclasse), realizar atividades que fujam da rotina, anular ou modificar as formas de avaliação, poderiam tornar o ambiente mais convidativo para que os participantes se sintam abertos para aquilo que se propõe - compreender, reverenciar, analisar criticamente, responsabilizar-se, e assim por diante.

Outra questão levantada pela autora em relação à $\mathrm{EH}$, que se aproxima da EA, é a da coerência. Ou seja, o aprendizado se daria, em grande medida, pelo exemplo, e para tanto os educadores humanitários deveriam viver aquilo que desejam ter como mensagem para os demais.

Por fim, tal como na EA crítica, a autora também enfatiza a importância de fomentar não apenas a responsabilidade quanto a escolhas individuais, mas, também, o potencial de cada um, no sentido de se envolver politicamente, influenciando, por exemplo, governos e setor privado para que também façam mudanças orientadas a um mundo mais compassivo.

As abordagens pedagógicas propostas por Zoe Weil (2004) para a EH se aproximam daquelas utilizadas na EA crítica ao sugerirem a análise de questões relacionadas à produção e consumo, desigualdades sociais, inter-relações entre questões ambientais e injustiças sociais, e, ao mesmo tempo, buscando provocar a sensibilização e o encantamento para com o mundo e a vida em geral, fomentando a proatividade por meio de exemplos positivos de lideranças e ativismo que buscam a paz, a justiça social e ambiental.

Selby (1995) indica, porém, que apesar do reconhecimento da pertinência de aproximação entre os dois campos, e da intenção de alguns educadores em fazê-lo, isso ainda está longe de ocorrer em todo seu potencial. Para o autor, existe uma tensão entre educadores humanitários e educadores ambientais que reside entre uma visão que prioriza as necessidades e direitos de cada indivíduo e outra que, ao priorizar o ambiente como um todo, acaba desconsiderando a individualidade de cada animal não humano. Ou seja, muitos educadores ambientais, na busca por uma visão holística da questão ambiental, perdem de vista as

\footnotetext{
13 Tal posicionamento foi explicitado, também, em dois importantes documentos internacionais que referenciam a educação ambiental crítica: A Carta da Terra e o Tratado de Educação Ambiental para Sociedades Sustentáveis e Responsabilidade Global, ambos produzidos durante a Rio-92.
} 
necessidades e os direitos de determinadas espécies, e, sobretudo, de membros específicos de cada espécie, formando uma visão dos animais apenas como parte do meio ambiente e não como indivíduos possuidores de direitos ${ }^{14}$. Essa abordagem gera uma contradição interna, pois ao se adotar uma EA holística, por definição, esta deve incluir tanto os ambientes naturais como os construídos. Assim, não seria possível excluir dela a consideração da vida de animais que estão, por exemplo, em fazendas industriais, laboratórios, zoológicos, aquários, circos e em centros urbanos - em lares ou nas ruas - como se estivessem fora do meio ambiente.

Weil (2004) concorda em que aí se encontra a principal diferença entre a EH e a EA: enquanto ambas se assemelham no objetivo de contribuir para a criação de um mundo onde os humanos vivam de forma pacífica e sustentável, se diferenciam no fato de que a educação humanitária também promove escolhas que diminuem o sofrimento não apenas de ecossistemas, espécies ou comunidades inteiras, mas também de pessoas e animais individualmente.

No Brasil, embora a literatura acadêmico-científica não explicite definições para o termo educação humanitária, a pertinência da aproximação de campos que considerem o respeito aos animais não humanos e as questões ambientais - seja na educação, ou nos movimentos sociais - tem sido apontada por autores como Bluwol (2010); Brügger (2004, 2008); Felipe (2013); Fernando (2009) e Winckler (2007), entre outros.

Para além disso, algumas ONGs, no Brasil, que trabalham em prol de animais não humanos, têm buscado incluir a educação humanitária ${ }^{15}$ na formação escolar básica, e, por vezes, os projetos apresentados se apoiam na parceria com projetos de $\mathrm{EA}^{16}$.

Da mesma forma, há uma busca pela aproximação de questões referentes aos direitos animais no âmbito legislativo, tendo como porta de entrada, por vezes, a legislação já existente de educação ambiental, como é o caso do Projeto de Lei 689/11, que prevê incentivo do Poder Público a campanhas contra o uso de peles de animais em roupas, além de incluir o debate sobre bem-estar animal entre os conteúdos abordados na educação ambiental formal. Segundo informativo da Câmara dos Deputados (2014, s/p), "o projeto altera a Política Nacional de Educação Ambiental (Lei 9.795/99), que já prevê, de forma genérica, o incentivo do Poder Público a "práticas educativas voltadas à sensibilização da coletividade sobre as questões ambientais', inclusive por meio de campanhas na mídia, em horário nobre".

Esses exemplos visam, apenas, ilustrar o fato de que alguns autores no Brasil consideram, assim como autores internacionais, que uma aproximação do campo da EH com a EA é pertinente; além de, na prática, observarem-se algumas iniciativas nesse sentido.

Como um primeiro passo para superar as lacunas e contradições apontadas por Selby (1995) e Weil (2004) e, assim, considerar as possibilidades de tornar a aproximação entre essas

\footnotetext{
${ }^{14}$ Além de ser abordada por Selby (1995), essa mesma questão foi destacada por Barry MacKay, fundador, exdiretor e membro honorário de diversas organizações ambientalistas e de defesa animal na América do Norte. Tal questão foi levantada na ocasião de uma entrevista realizada em abril de 2013, em Toronto, Canadá, durante estágio de pesquisa de pós-doutorado realizado naquele país.

${ }^{15}$ Quanto à apropriação do conceito de educação humanitária por essas instituições, ressalta-se que parte delas derivam de ONGs internacionais que têm escritórios no Brasil, e utilizam os conceitos já definidos pela instituiçãosede no exterior. Vale notar que, se por um lado, muitas vezes essas definições têm aparentemente uma amplitude significativa no que se refere a relacionar questões sobre a opressão e violência de animais humanos e não humanos, na prática vê-se que muitos dos projetos e programas dessas ONGs têm uma abordagem que se limita a tratar de questões de bem-estar de algumas espécies de animais.

${ }^{16}$ Exemplos podem ser vistos em parcerias entre a World Animal Protection (WSPA), Ibama e Ministérios da Educação e do Meio Ambiente em projeto realizado no Distrito Federal (http://www.projetogap.org.br/noticia/projeto-a-escola-e-o-bicho/), ou com Secretarias Municipais de Educação, como nos casos de Petrópolis - RJ, Vitória - ES (http://aoma-sd.blogspot.com.br/2010/09/wspa-amplia-acoes-deeducacao.html), e Santo André - SP (http://www2.santoandre.sp.gov.br/index.php/noticias/item/5085Professores-serao-capacitados-para-educacao-ambiental-em-Santo-Andre).
} 
áreas mais profícua, na próxima seção apresentamos uma amostra do pensamento de educadores que estão atuando nesses campos no Brasil, a respeito dessas aproximações.

\section{O que pensam educadores brasileiros sobre uma aproximação entre EA e EH}

Para realizar o levantamento sobre o que pensam educadores brasileiros sobre esse tema, foram elaborados dois tipos de questionários, designados, aqui, de I e II. Os questionários I foram enviados a pesquisadores, professores - universitários e do ensino médio - e ativistas que se identificam com o trabalho nas áreas de educação humanitária e/ou educação ambiental.

A seleção dos entrevistados foi feita a partir da identificação de lideranças, tanto no campo dos movimentos sociais, como de grupos de pesquisa baseados em universidades, com atuação nas áreas de educação humanitária e ambiental. Alguns entrevistados encontravam-se nos dois campos, e outros tinham intersecção entre a atuação no ensino médio e movimentos sociais. Os entrevistados com atuação junto ao ensino médio (que, no caso, era em escolas públicas) e os que se dedicam ao ativismo de rua têm maior contato com a base da população, enquanto os docentes e pesquisadores de universidades acabam atuando junto a um público que ainda se encontra, até certa medida, mais elitizado. Assim, essa amostra nos permitiu ter um panorama razoável sobre a existência e possibilidades de atuação educativa junto a diferentes setores da sociedade.

Os questionários buscavam avaliar a percepção dos respondentes quanto à pertinência da integração entre as áreas, incluindo perguntas sobre suas linhas de atuação, se já haviam realizado projetos e/ou pesquisa integrando ambas as áreas, ou se conheciam colegas ou grupos que o houvessem feito. Os questionários foram enviados por $e$-mail a dez pessoas de cada grupo - perfazendo, assim, um total de vinte questionários enviados - acompanhados de uma carta de apresentação contextualizando os objetivos de pesquisa a eles relacionados. A taxa de retorno foi de $40 \%$ no grupo dos educadores humanitários e $30 \%$ no grupo dos educadores ambientais, de modo que as respostas oferecem dados de importância qualitativa, mais do que quantitativa.

Os questionários II foram direcionados aos participantes de um Simpósio de Políticas Públicas de Educação Ambiental, que incluiu educadores ambientais atuantes em municípios, escolas e Instituições de Educação Superior de diversas regiões do país. Decidiu-se por aplicar o questionário a participantes desse evento devido à oportunidade de se acessar a percepção de atores da EA de diversos segmentos e regiões do país sobre o tema pesquisado, ainda que essa opção tenha causado um desequilíbrio no número de educadores humanitários e educadores ambientais amostrados.

O questionário buscava avaliar se os educadores ambientais consideravam pertinente a aproximação com questões referentes à causa animal e, em caso afirmativo, com quais dessas questões; bem como se eles tinham conhecimento de políticas públicas, em formulação ou vigentes em seus municípios, que as abordassem e, em caso afirmativo, se estas tinham relação com políticas públicas de EA. Com autorização da organização do evento, o questionário foi enviado a todos os participantes por e-mail, logo após o término do evento. Nesse caso, a taxa de retorno foi de $19,25 \%$, o que corresponde a um número real de 52 respondentes ${ }^{17}$.

No que se refere ao questionário I, $100 \%$ daqueles que o responderam disseram considerar pertinente uma aproximação entre os dois campos educacionais, por serem indissociáveis tanto em seus princípios quanto em seus efeitos práticos: Trabalhar um (tema) $e$ não trabalhar o outro é uma contradição em si, afirmou um dos respondentes. Apesar disso,

\footnotetext{
${ }^{17}$ Em termos de método, gostaríamos de ter colhido uma amostragem semelhante entre educadores humanitários e educadores ambientais sobre o tema. Entretanto, as oportunidades que surgiram ao longo da pesquisa viabilizaram a aplicação de questionários a um número consideravelmente maior de educadores ambientais - o que reflete, inclusive, o fato da EA ser uma área mais consolidada do que a EH no Brasil.
} 
apenas 42,8\% destes (ou seja, apenas 3 respondentes) afirmaram já haver realizado algum trabalho (publicação, projeto de pesquisa, ensino ou extensão), abordando, ambos os temas de forma integrada.

Quanto ao questionário II, 98,08\% dos respondentes (51 pessoas) consideraram pertinente fazer a aproximação entre os dois campos. Ao perguntarmos, a estes que responderam positivamente, quais questões referentes à ética e direitos dos animais não humanos deveriam ser contemplados pela EA, obtivemos as seguintes respostas (Tabela 1):

Tabela 1 - Respostas dos participantes do Simpósio de Políticas Públicas de Educação Ambiental sobre os temas relacionados à ética e direitos animais que consideram que deveriam ser aproximados à EA

\begin{tabular}{|c|c|c|}
\hline Tema & $\begin{array}{lrr}\text { Porcentagem }(\%) & \text { de } \\
\text { respondentes } & & \text { que } \\
\text { assinalaram esse tema } & \end{array}$ & $\begin{array}{l}\text { Número de } \\
\text { respondentes que } \\
\text { citaram o tema }\end{array}$ \\
\hline Tráfico de animais silvestres & 100 & 51 \\
\hline $\begin{array}{l}\text { Animais utilizados para confecção de } \\
\text { vestimentas }\end{array}$ & 92,16 & 47 \\
\hline Experimentação animal & 76,47 & 39 \\
\hline Animais em entretenimento & 76,47 & 39 \\
\hline Animais utilizados para alimentação & 68,63 & 35 \\
\hline Animais de companhia (pets) & 56,86 & 29 \\
\hline
\end{tabular}

Ao perguntarmos se conheciam políticas públicas ou projetos em seus municípios que abordassem alguns dos temas citados na questão anterior, 28,85\% (15 respondentes) responderam positivamente, e $26,92 \%$ (14 respondentes) indicaram sobre quais temas estas tratam, conforme tabela abaixo:

Tabela 2 - Temas abordados por Políticas Públicas, programas, leis ou ações municipais, segundo os respondentes

\begin{tabular}{l|l|l} 
Tema & $\begin{array}{l}\text { Porcentagem (\%) de } \\
\text { respondentes que } \\
\text { citaram esse tema } \\
\text { (dentre os 14 que } \\
\text { responderam) }\end{array}$ & $\begin{array}{l}\text { Número de } \\
\text { respondentes que } \\
\text { citaram o tema }\end{array}$ \\
\hline $\begin{array}{l}\text { Animais de companhia (ações, programas e } \\
\text { legislação referentes à castração, adoção e posse } \\
\text { responsável de animais de companhia) }\end{array}$ & 50 & 7 \\
\hline $\begin{array}{l}\text { Animais silvestres (ações, programas, legislação e } \\
\text { instituições relacionadas ao encaminhamento, } \\
\text { triagem, tratamento e reabilitação de animais } \\
\text { silvestres, educação relacionada ao tráfico de animais } \\
\text { etc.) }\end{array}$ & 35,7 & 5 \\
\hline $\begin{array}{l}\text { Experimentação animal (leis, regulamentações, } \\
\text { instruções normativas e comitês de ética para tratar } \\
\text { do tema) }\end{array}$ & 14,2 & 2 \\
\hline Animais em entretenimento (legislação) & 7,1 & 1 \\
\hline Leis referentes a maus-tratos aos animais em geral & 7,1 & 1 \\
\hline Não especificou & 7,1 & 1 \\
\hline
\end{tabular}

Por fim, os respondentes indicaram que $42,11 \%$ dessas iniciativas tinham alguma relação com iniciativas de educação ambiental. A natureza das políticas públicas, programas ou projetos aos quais essas iniciativas se relacionam foram citados, conforme a Tabela 3. 
Tabela 3 - natureza das políticas, programas e projetos que abordam questões relacionadas aos animais não humanos e que têm relação com iniciativas (políticas, programas ou projetos) no campo da EA.

\begin{tabular}{|c|c|c|}
\hline Tema & 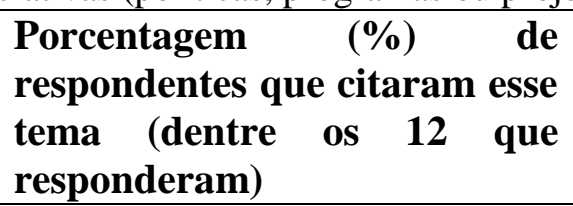 & $\begin{array}{l}\text { Número de } \\
\text { respondentes que } \\
\text { citaram o tema }\end{array}$ \\
\hline $\begin{array}{l}\text { Programas do IBAMA presentes } \\
\text { no município }\end{array}$ & 25 & 3 \\
\hline Recuperação de praças públicas & 8,33 & 1 \\
\hline $\begin{array}{l}\text { Abordagens transversais em } \\
\text { projetos, programas e política de } \\
\text { EA do município (Meio } \\
\text { Ambiente, Consumo Consciente, } \\
\text { Segurança Alimentar) }\end{array}$ & 8,33 & 1 \\
\hline $\begin{array}{l}\text { Projetos de Educação Ambiental } \\
\text { da Rede Municipal de Ensino } \\
\text { (relacionados ao tema de } \\
\text { microfauna, fauna silvestre, } \\
\text { exótica e fauna urbana) }\end{array}$ & 8,33 & 1 \\
\hline $\begin{array}{l}\text { Projeto Escola da Amazônia e } \\
\text { Projeto Educação para a } \\
\text { Sustentabilidade }\end{array}$ & 8,33 & 1 \\
\hline $\begin{array}{l}\text { Projetos relacionados a UCs, } \\
\text { zoológicos, espécies-bandeira } \\
\text { regionais }\end{array}$ & 8,33 & 1 \\
\hline $\begin{array}{l}\text { Projetos em IES relacionado a } \\
\text { alimentação saudável, incluindo } \\
\text { vegetariana e vegana }\end{array}$ & 8,33 & 1 \\
\hline Programa Mais Educação & 8,33 & 1 \\
\hline Respostas imprecisas & 25 & 3 \\
\hline
\end{tabular}

Algumas considerações se fazem necessárias com relação aos dados apresentados. Em primeiro lugar, vale ressaltar que é possível que tenham respondido à demanda de pesquisa justamente aqueles que consideram que a aproximação entre as duas áreas em questão é importante. Assim, reconhecemos que as respostas obtidas não podem ser tomadas como significativas da visão geral dos educadores (humanitários e ambientais) com relação ao tema. Por outro lado, percebe-se que questões referentes aos animais não humanos vêm ganhando atenção nos últimos anos, e o fato de haver uma parcela de professores - de escolas básicas à educação superior - bem como gestores municipais interessados em abrir espaço para incluir esse tema, seja na educação ou em políticas públicas municipais de EA, pode ser considerado um avanço.

No que se refere ao segundo questionário, o fato de $100 \%$ dos educadores ambientais que consideraram pertinente a aproximação entre os campos de EH e EA compreenderem que tal aproximação é pertinente quando o tema tratado é o de tráfico de animais silvestres, e uma parcela consideravelmente menor - 68,63\% - considerar que é pertinente a questão dos animais usados para alimentação, denota que ainda existe uma visão conservacionista - e conservadora - por parte de educadores ambientais nesse sentido. Ou seja, se considerarmos que os efeitos da produção industrial de alimentos de origem animal são possivelmente mais nefastos ao meio ambiente que o tráfico de animais silvestres, e que tal produção traz sérios questionamentos 
éticos no que se refere ao respeito à vida, o peso dessa questão ainda não está refletido na opinião dos educadores ambientais que participaram da pesquisa.

Vale notar que observações provenientes da vivência no campo da EA, por parte dos autores, corroboram essa percepção. A questão da ética para com os animais não humanos, além de estar pouco presente na pauta de reuniões, temas de artigos ou trabalhos apresentados em congressos ou projetos acadêmicos (como indicam os resultados dos questionários I), tampouco é incorporada em outras dimensões de eventos da área. Assim, em congressos de EA, frequentemente não há, por exemplo, opções de alimentação vegetariana (sobretudo vegetariana estrita), ficando a discussão sobre o modelo de produção alimentar - que, segundo a FAO (2013), é um dos temas que mais impactam atualmente o ambiente global, e portanto deve ser revisto com urgência - fora da pauta de diálogo formal e informal desses eventos.

Falta, assim, ampliar a formação para uma abordagem mais complexa das implicações éticas e pragmáticas dessas inter-relações, se buscamos uma ética de respeito à vida. Caso contrário, corre-se o risco de se fomentar justamente o efeito contrário, como em exemplo trazido por Selby (1995) em que a falta de diálogo entre essas duas áreas - e, inclusive, sobre as tensões que as permeiam - fez com que um crescimento da consciência ambiental nos anos 80 gerasse uma demanda por produtos mais ambientalmente amigáveis e seguros, o que, por sua vez, incentivou um aumento na realização de testes de toxicidade em animais, causando, assim, mais sofrimento e morte.

Por fim, ressaltamos que as abordagens das questões que permeiam as diversas formas de exploração animal não são triviais - nem, portanto, uma aproximação entre a EH e a EA. Os educadores ambientais podem evitar lidar com temas referentes às formas como nos relacionamos com os outros animais por questões práticas, que vão desde o receio de serem rotulados como extremistas, até a dificuldade de lidar com questões que adentram o lar - tais como o que comer, o que vestir, quais produtos de higiene pessoal ou limpeza consumir. Ao se abordar, por exemplo, questões sobre animais utilizados na alimentação, pode-se desvelar informações que, além de perturbadoras, podem levar um público que se considera partidário da causa animal a ver-se como constituindo parte do problema, e não da solução. Assim, se questões como essa não forem abordadas de forma acolhedora, e fomentando a proatividade, podem gerar um afastamento do público em relação ao tema, ao invés de uma aproximação, contrariando os objetivos de uma abordagem pedagógica em prol dos animais. Dado o potencial dessas questões em provocar conflitos internos sobre as necessidades e possibilidades de mudanças, portanto, abordagens pedagógicas que promovam esse diálogo devem ser construídas com muita atenção, visando minimizar as possibilidades de surtir efeitos contrários àqueles desejados ${ }^{18}$.

\section{Considerações finais: potencialidades, limites e próximos passos}

Na introdução ao livro "The Power and promise of humane education", de Zoe Weil, a pesquisadora e ativista pelos direitos animais Jane Goodall (2004) define a educação humanitária como um amplo campo de estudos que traz as conexões entre todas as formas de justiça social, analisando questões referentes à opressão humana, à exploração animal e à degradação ambiental, e que propõe formas de vivermos com respeito e compaixão pelos demais, ajudando a construir um mundo mais seguro, pacífico, sustentável e menos cruel.

Adotando uma definição semelhante, Selby (1995) coloca que, apesar desses objetivos louváveis, na prática o foco da $\mathrm{EH}$ tem se reduzido a questões relacionadas aos animais não humanos, e algum esforço está sendo feito para aproximar questões ambientais, porém os

\footnotetext{
${ }^{18}$ A dificuldade em se lidar pedagogicamente com essas questões, bem como algumas propostas de como fazê-lo, tem sido abordadas em outros publicações, tais como DeMello (2010) e Engel e Jenni (2010).
} 
demais temas - tais como equidade, justiça, desenvolvimento e paz - não têm sido incorporados, de forma consistente e estruturada, nos programas de EH (ao menos, com base em materiais curriculares dos EUA, Canadá e Reino Unido analisados pelo autor ${ }^{19}$.

A importância de se buscar essas aproximações reside no fato de que o diálogo entre essas vertentes educacionais pode chamar a atenção para lacunas conceituais, pedagógicas e de conteúdo e, nesse processo, será possível identificar novos aliados. Uma vez identificadas tais lacunas e aliados, cresce significativamente o potencial em se abordar, efetivamente, temas que são cruciais para o momento civilizatório atual, podendo fazer enorme diferença para o futuro de pessoas, de animais e do planeta, individual e coletivamente.

Visando potencializar essas aproximações, um dos caminhos aqui sugeridos é olharmos para os estudos críticos animais (CAS), no sentido de se considerar a educação de adultos para o tema com a mesma importância que se considera a de crianças - e, sobretudo, adultos que tenham maiores chances de incidir na formulação de políticas públicas e/ou de serem lideranças e formadores de opinião em outros campos - bem como no posicionamento explícito (não neutro), ainda que não necessariamente intransigente, das causas defendidas.

Por fim, acreditamos que a plena implementação da EH, em sua definição, implica não apenas uma efetiva aproximação com a EA, mas também com as demais vertentes das educações progressistas citadas no presente artigo. Para tanto, esse olhar para o que vem sendo feito nos CAS pode representar um avanço, também no sentido de inserir na EH um olhar ainda mais inclusivo e revolucionário, a partir da perspectiva abolicionista ${ }^{20}$.

Para o estado da arte da EA no Brasil - e se tomarmos como amostra os temas trazidos pelos questionários aplicados na pesquisa vinculada ao presente artigo - há, ainda, um caminho a ser trilhado, no sentido de ampliar um viés ainda bastante atrelado a uma visão conservacionista, para uma ética da vida que considere o valor inerente de todos e de cada um, sejam eles indivíduos de espécies ameaçadas de extinção ou pertencentes a espécies abundantes e pouco valorizadas sob essa perspectiva. Para cada indivíduo, o valor de sua vida, de seu bemestar e de sua liberdade é o mesmo, independente do valor que lhes seja atribuído por outros, e, assim, deveria ser considerado a partir de uma ética não antropocêntrica, que respeite verdadeiramente todas as formas de vida. Por outro lado, a abertura para dialogar sobre o tema, indicada nas respostas aos questionários, nos leva a crer que os educadores ambientais - ou, ao menos, uma parcela deles - estão atentos e abertos a tais questões, e que desempenharão, cada vez mais, um importante papel na inclusão desses temas em sua atuação cotidiana, contribuindo para a construção de um planeta mais justo, sustentável e pacífico para todos.

\section{Referências}

ARAÚJO, H. et al. Introdução. In: FERRARO JR. L.A. (Org.). Encontros e Caminhos: Formação de Educador(es) Ambientais e Coletivos Educadores. Brasília: Ministério do Meio Ambiente, 2005. p. 9-12.

BLUWOL, D. Z. Ética libertária interdependente - veganismo, ecologia, saúde, política e liberdade. In: ANDRADE, S. (Org.). Visão Abolicionista: ética e direitos animais. São Paulo: Libra Três, 2010. p.73-82.

\footnotetext{
${ }^{19}$ Essa questão também é apontada por Humes (2008), ao indicar que educação humanitária não tem sido capaz de incluir a injustiça e opressão a humanos com profundidade.

${ }^{20}$ Vale ressaltar, porém, que quando sugerimos os CAS como um caminho a ser considerado pela EH não propomos uma simples mudança de nomeações, mas, sim, um reconhecimento do amadurecimento do campo, acolhendo as ideias anteriores e avançando a partir delas, considerando o contexto histórico em que os conceitos foram criados e aplicados.
} 
BRÜGGER, P. Amigo Animal: reflexões interdisciplinares sobre educação e meio ambiente. Florianópolis: Letras Contemporâneas, 2004.

BRÜGGER, P. Dieta Vegana e sustentabilidade (g)local. Pensata Animal [online], s/v, n.17, s/p, Nov. 2008. Disponível em: <http://www.pensataanimal.net/artigos/45-paulabrugger/77dieta-vegana>. Acesso em: 28 jun. 2012.

BRÜGGER, P. Para além da dicotomia abolicionismo versus bem-estarismo. Agência de Notícias de Direitos Animais. [2009]. Disponível em: < http://www.anda.jor.br/26/11/2009/para-alem-da-dicotomia-abolicionismo-versus-bemestarismo>. Acesso em: 28 jun. 2012.

CÂMARA DOS DEPUTADOS. Projeto de Lei 689/2011. Disponível em: <http://www.camara.gov.br/proposicoesWeb/fichadetramitacao?idProposicao=494451> Acesso em: 30 ago. 2014.

CASTELLANO, M. A participação no Campinho da Independência: caminhos para sociedades sustentáveis. Ano de depósito: 2002. 238 f. Dissertação (Mestrado em Ciência ambiental) Universidade de São Paulo, São Paulo, 2002.

DeMELLO, M. Introduction to Human-Animal Studies. In: (Ed.). Teaching the animal: Human-Animal Studies across the disciplines. Brooklyn, NY: Lantern Books, 2010. p. xi-xix.

ENGEL Jr. M.; JENNI, K. Examined lives: teaching Human-Animal Studies in philosophy. In: DeMELLO, M. (Ed.). Teaching the animal: Human-Animal Studies across the disciplines. Brooklyn, NY: Lantern Books, 2010. p. 60-102.

FOOD AND AGRICULTURE ORGANIZATION. FAO. Livestock's long shadow: environmental issues and options. [2013]. Disponível em: $<$ http://www.fao.org/agriculture/lead/lead-resources/newsletter2/newsletter-09/en/>. Acesso em: 4 de jun. 2014.

FELIPE, S. T. Direitos animais: desdobramentos das pregas morais. In: ANDRADE, S. (Org.). Visão Abolicionista: ética e direitos animais. São Paulo: Libra Três, 2010. p.11-28

FELIPE, S. T. Devastação alimentar e ambiental. Pensata Animal [online], s/v, n.31, s/p, Out. 2013. Disponível em: <http://www.pensataanimal.net/pensadores/152-sonia-t-felipe/386implicacoes-eticas-ambientais-e-nutricionais-do-consumo-de-leite-bovino-uma-abordagemcritica-devastacao-alimentar-e-ambiental_. Acesso em: 10 jul. 2014.

FERNANDO, R. Ambientalismo e Direitos Animais: uma simbiose fraternal. Pensata Animal [online], s/v, n. 25, s/p, Jul. 2009. Disponível em: http://www.pensataanimal.net/arquivos-dapensata/77-robsonfernando/307-ambientalismo-e-direitos-animais-uma-simbiose-fraternal.

Acesso em: 2 set. 2013.

FÓRUM GLOBAL. The Earth Charter. 1992. Disponível em: http://www.earthcharterinaction.org/content/pages/read-the-charter.html. Acesso em: 8 mai. 2013. 
FÓRUM GLOBAL. Treaty on Environmental Education for Sustainable Societies and Global Responsibility. $1992 . \quad$ Disponível em: http://www.stakeholderforum.org/fileadmin/files/Earth_Summit_2012/1992_treaties/Treaty_o n_Environmental_Education_for_Sustainable_Societies_and_Global_Responsibility.pdf. Acesso em: 8 mai. 2013.

FRANCIONE , G.; GARNER, R. The animal rights debate: abolition or regulation? New York. Columbia University Press, 2010.

GOODALL, J. Introduction. In: WEIL, Z. The Power and promise of humane education. Canadá: New Society Publishers, 2004. p.1-8

GREIF, S. Educação humanitária. Pensata animal [online], s/v, n.4, s/p, Ago. 2007. Disponível em: $\quad$ http://www.pensataanimal.net/arquivos-da-pensata/43-sergiogreif/136-educacaohumanitaria. Acesso em: 14 mai. 2014.

GREIF, S. Em defesa dos animais: uma análise crítica da argumentação de um filósofo bemestarista. Agência de Notícias de Direitos Animais [2009]. Disponível em: http://www.anda.jor.br/03/11/2009/em-defesa-dos-direitos-animais-uma-analise-critica-daargumentacao-de-um-filosofo-bem-estarista. Acesso em: 25 fev. 2011.

HUMES, B. Moving toward a liberatory pedagogy for all species: mapping the need for dialogue between humane and anti-oppressive education. Green Theory and Practice: A Journal of Ecopedagogy, s/1, v.4, n.1, p.65-85, 2008.

INSTITUTE FOR HUMANE EDUCATION - IHE. Disponível em: $<$ http://humaneeducation.org/>. Acesso em: 7 jul. 2014.

KAHN, R.; HUMES, B. Marching out from Ultima Thule: critical counterstories of emancipatory educators working at the intersection of human rights, animal rights, and planetary sustainability. Canadian Journal of Environmental Education, Thunder Bay, Canada. v.14, s/n, p.179-195, 2009.

LEIS, H. R. A Modernidade Insustentável - As Críticas do Ambientalismo à Sociedade Contemporânea. Petrópolis: Vozes; Santa Catarina: UFSC, 1999.

LIMA, J. E. R. Vozes do Silêncio. Cultura científica: ideologia e alienação no discurso sobre vivissecção. São Paulo: Instituto Nina Rosa, 2008.

NACONECY, C. Bem-Estar Animal ou Libertação Animal?: uma análise crítica da argumentação anti bem-estarista de Gary Francione. Revista Brasileira de Direito Animal, Salvador, Ano 4, n.5, p.235-267, Jan./Dez. 2009.

NOCELLA II, A.J. et al. Introduction: The Emergence of Critical Animal Studies: The Rise of Intersectional Animal Liberation. In: (Eds.) Defining Critical Animal Studies: an intersectional social justice approach for liberation. New York: Peter Lang, 2014. p.xix-xxxvi.

RED DE EDUCACIÓN POPULAR Y ECOLOGÍA/CONSEJO DE EDUCACIÓN POPULAR DE AMERICA LATINA Y EL CARIBE - REPEC/CEAAL. Educación Popular Ambiental en América Latina. Pátzcuaro Michoacán: CESE, 1994. 
SANTANA, H. J. Espírito animal e o fundamento moral do especismo. Revista Brasileira de Direito Animal, Salvador, Ano 1, n.1, p.37-65, Jan./Dez. 2006.

SELBY, D. Earthkind: A teacher's Handbook on Humane Education. England: Trentham Books Limited, 1995.

SOUZA, J. F. de J. O olhar da bioética sobre a representação social de animais no contexto da educação humanitária. 2012. 87f. Dissertação (Mestrado em Bioética) - Universidade de Brasília, Brasília, 2012.

SOUZA, J.F de S.; SHIMIZU, H.E. Representação social acerca dos animais e bioética de proteção: subsídios à construção da educação humanitária. Revista Bioética, São Paulo, v.21, n.3. p. 546-56, 2013.

TASSARA, E. T. de O.; ARDANS, O. Intervenção psicossocial: Desvendando o sujeito histórico e desvelando os fundamentos da educação ambiental crítica. In: FERRARO JR., L.A. (Org.). Encontros e Caminhos: Formação de Educador(es) Ambientais e Coletivos Educadores. Brasília: MMA, 2005. p.203-216.

TAVOLARO, S. B. F. Ação comunicativa. In: FERRARO JR., L.A. (Org.). Encontros $e$ Caminhos: Formação de Educador(es) Ambientais e Coletivos Educadores. Brasília: MMA, 2005. p.15-25.

WEIL, Z. The power and promise of Humane Education. Canadá: New Society Publishers, 2004.

WINCKLER, M. Vegetarianismo: condição inescapável para o mundo melhor que todos queremos. Pensata animal [online], s/v, n.1, s/p, Mai. 2007. Disponível em: http://www.pensataanimal.net/arquivos-da-pensata/53-marlywinckler/110-vegetarianismocondicao-inescapavel. Acesso em: 3 jul. 2014.

UNTI, B.; DeROSA, B. Humane education: Past, present and future. In: SALEM, D. J.; ROWAN, A.N. (Eds.). The state of the animals II. Washington, DC: Humane Society Press, 2003. p. 27-50. 